\title{
PERCUTANEOUS TRANSLUMINAL AORTIC ANGIOPLASTY WITH STENTING FOR IN-STENT RESTENOSIS IN TAKAYASU'S ARTERITIS
}

\author{
Nandhakumar Vasu1, Jaishankar Krishnamoorthy², Srinivasan Narayanan³, Mullasari Ajit Sankaradas ${ }^{4}$ \\ 1 Junior Consultant, Department of Cardiology, Institute of Cardio-Vascular Diseases, Madras Medical Mission. \\ ${ }^{2}$ Senior Consultant, Department of Cardiology, Institute of Cardio-Vascular Diseases, Madras Medical Mission. \\ ${ }^{3}$ Consultant, Department of Cardiology, Institute of Cardio-Vascular diseases, Madras Medical Mission. \\ ${ }^{4}$ Director \& Senior Consultant, Department of Cardiology, Institute of Cardio-Vascular Diseases, Madras Medical Mission.
}

\begin{abstract}
A 37-year-old female patient with coarctation of abdominal aorta and right axillary artery stenosis due to Takayasu's arteritis underwent Percutaneous Transluminal Angioplasty [PTA] with stents. After one and a half years, she developed In-Stent Restenosis [ISR] of both stents in abdominal aorta and right axillary artery because of discontinuation of corticosteroid and reactivation of disease. She underwent successful repeat angioplasty and stenting for ISR of abdominal aorta. She was discharged with optimal disease modifying drugs and antihypertensive medicines. Her symptoms were improved on 3 months follow-up and she was planned for staged PTA to ISR of right axillary artery.
\end{abstract}

\section{KEYWORDS}

Takayasu Arteritis, Percutaneous Transluminal Angioplasty, In-Stent Restenosis.

HOW TO CITE THIS ARTICLE: Vasu N, Krishnamoorthy J, Narayanan S, et al. Percutaneous transluminal aortic angioplasty with stenting for in-stent restenosis in Takayasu's arteritis. J. Evolution Med. Dent. Sci. 2016;5(63):4500-4501, DOI: $10.14260 /$ jemds/2016/1026

\section{INTRODUCTION}

Takayasu's arteritis is a rare chronic inflammatory arteritis of large blood vessels, predominantly involving the aorta and its major branches. The symptoms of this disease are hypertension, aortic regurgitation and end-organ ischaemia. The modes of death are heart failure, myocardial infarction, cerebrovascular accident and renal failure, because of angiostenosis or stricture of major arteries. ${ }^{1}$ Therefore, aggressive treatment is required for patients suffering with major complications and a progressive disease course. ${ }^{2}$ To diagnose Takayasu's arteritis, the American College of Rheumatology defined specific diagnostic criteria for this disorder in $1990 .^{3}$ But angiography is the gold standard for diagnosis. With the advanced imaging technology and interventional hardware, Percutaneous Transluminal Angioplasty [PTA] and stenting is the treatment of choice for stenotic lesions. However, restenosis rates are higher than that of atherosclerotic lesions.4,5 We report a case of ISR of abdominal coarctation due to Takayasu's arteritis who underwent successful redo-PTA with stent.

\section{Case Report}

A 37-year-old female presented with severe claudication of both lower limbs and right upper limb of three months' duration, which was gradually worsening. On examination right upper limb and both lower limb pulses were feeble, but left upper limb and both carotid pulses were normal. Her blood pressure in the left upper limb was 198/110 mmHg. Right

Financial or Other, Competing Interest: None.

Submission 29-04-2016, Peer Review 22-07-2016,

Acceptance 28-07-2016, Published 08-08-2016.

Corresponding Author:

Dr. Nandhakumar Vasu,

Junior Consultant,

Institute of Cardio-Vascular Diseases,

Madras Medical Mission,

\#4-A, Dr.J. J. Nagar,

Mogappair, Chennai-600037, Tamilnadu.

E-mail: nandhacard2013@gmail.com

DOI: $10.14260 /$ jemds/2016/1026 upper limb was 110/90 mmHg and both lower limbs showed $150 / 100 \mathrm{mmHg}$. There were bruits in periumbilical and right axillary regions. On examination of cardiovascular system, there was a left ventricular S4 and no murmurs.

ECG revealed left ventricular hypertrophy. Her haemoglobin was $9.7 \mathrm{~g} / \mathrm{dL}$, PCV-30.5\%, ESR- $51 \mathrm{~mm} /$ hour and biochemistry was within normal limits. There was left ventricular hypertrophy and good biventricular function on echocardiogram.

Two years ago, she had undergone PTA and Stent deployment to right axillary artery using 7 x $60 \mathrm{~mm}$ complete SE iliac Medtronic stent and abdominal aorta was stented using 14 x $80 \mathrm{~cm}$ COOK ZILVER 635 and 14 x $60 \mathrm{~cm} \mathrm{COOK}$ ZILVER 635 two self-expanding stents, which was expanded up to $9 \mathrm{~mm}$. She was put on three antihypertensive medications [Extended release nifedipine $20 \mathrm{mg}$ once daily, metoprolol $50 \mathrm{mg}$ twice daily and alpha methyldopa $500 \mathrm{mg}$ twice daily] along with prednisolone $40 \mathrm{mg}$ once a day, dual antiplatelets [Aspirin and clopidogrel] and pantoprazole. Also she was advised to review after 6 months for graded dilatations of aortic stents. But she lost for follow-up and stopped corticosteroids.

CT aortogram during the present admission showed diffusely narrowed abdominal aortic stent [Fig. 1A and 1B] tightest lesion at the distal end of stent and totally occluded right axillary artery stent and distal vessel was filling via collaterals.

Through right femoral approach, aortogram was done to delineate aortic stent and abdominal aortic branches. Pressure gradient was checked from the proximal end of stent in descending aorta up to aorto-iliac bifurcation using 5F MultiTrack catheter. There was significant increase in gradient towards lower end of abdominal aortic stent extending after the stent distally at superior mesenteric arterial level. Serial dilatations were done at the mid and distal end of the stent using $8 \times 20 \mathrm{~mm}$ conquest pro-balloon followed by $10 \times 20 \mathrm{~mm}$ conquest pro-balloon. Gradients were recorded after balloon dilatations. A 9 × 57 mm Express LD balloon expandable stent was deployed across the distal end of abdominal aortic stent 
extending up to superior mesenteric arterial level. Final angiogram showed minimal gradient with well-opposed stent without any dissection or flap [Fig. 2A and 2B].

Patient was discharged with dual antiplatelets, antihypertensive drugs [Amlodipine $10 \mathrm{mg}$ once daily, hydrochlorothiazide $12.5 \mathrm{mg}$ once daily, metoprolol $50 \mathrm{mg}$ twice daily and alpha methyldopa $500 \mathrm{mg}$ twice daily] along with $40 \mathrm{mg}$ of prednisolone and pantoprazole with the plan of axillary artery stenting as a staged procedure. On follow-up at 3 months, she is symptomatically better with an ESR of $31 \mathrm{~mm}$ per hour.

\begin{tabular}{|c|c|c|}
\hline Site & $\begin{array}{l}\text { Pre-Procedure } \\
\text { (mmHg) }\end{array}$ & $\begin{array}{l}\text { Post-Procedure } \\
\text { (mmHg) }\end{array}$ \\
\hline $\begin{array}{l}\text { Above the Stent at } \\
\text { Thoracic Aorta }\end{array}$ & $215 / 86 / 138$ & $263 / 104 / 170$ \\
\hline Proximal Stent & $215 / 86 / 138$ & $253 / 99 / 158$ \\
\hline $\begin{array}{l}\text { Proximal End of the } \\
\text { Second Stent }\end{array}$ & $150 / 76 / 103$ & $231 / 96 / 151$ \\
\hline $\begin{array}{l}\text { Lower End of the } \\
\text { Second Stent }\end{array}$ & $125 / 74 / 97$ & $227 / 90 / 147$ \\
\hline Femoral Artery & $90 / 58 / 72$ & $228 / 92 / 140$ \\
\hline
\end{tabular}

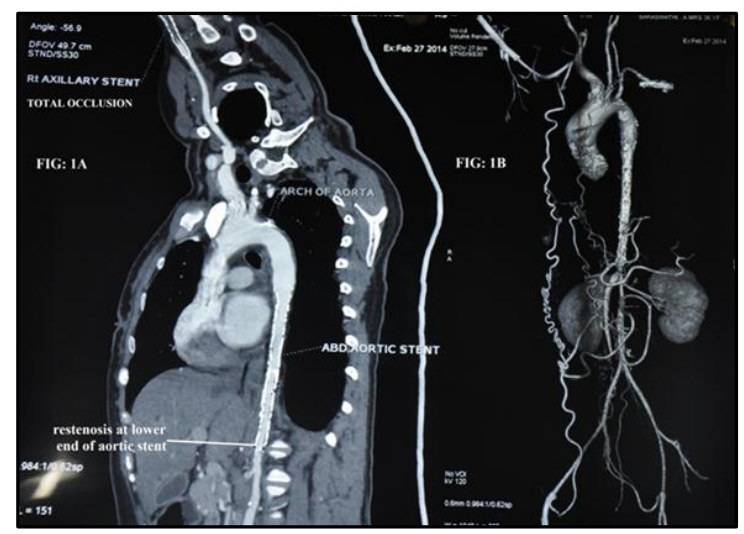

Fig. 1A \& 1B: Reconstructed CT images revealed diffuse narrowing of abdominal aorta in stented segment [Solid White Line] \& totally occulated right axillary artery stent

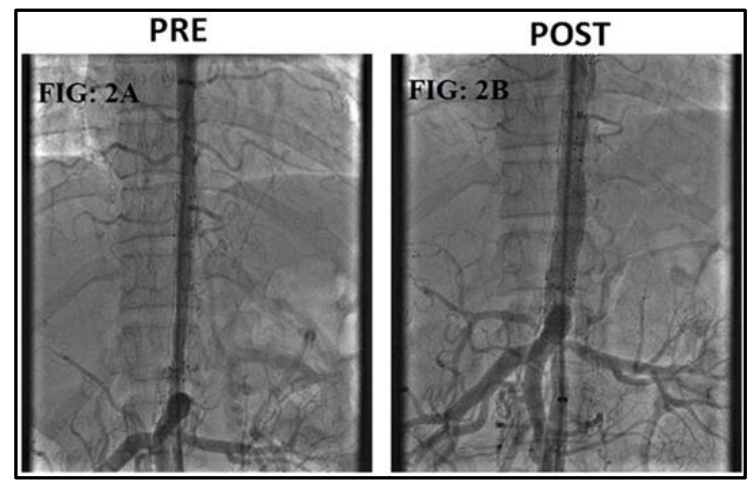

Fig. 2A \& 2B: Aortogram before and after redo PTA with stent

\section{DISCUSSION}

Takayasu's arteritis is a chronic inflammatory arteritis affecting large vessels, predominantly the aorta and its main branches. It is also known as pulseless disease, occlusive thromboaortopathy and Martorell syndrome. ${ }^{6}$ Vessel inflammation leads to wall thickening, fibrosis, stenosis and thrombus formation, whereas acute inflammation can destroy the arterial media and lead to aneurysm formation. It is most commonly seen in Japan, South East Asia, India and Mexico. In 1990, it was included in the list of intractable diseases maintained by the Japanese government. ${ }^{7}$
Although medical management with corticosteroids has been widely used to control the inflammation, revascularization must be considered when the symptoms become resistant to medication. Many surgical techniques have been reported, but they carry high morbidity and mortality rates and are associated with problems of stenosis or aneurysm formation at the anastomotic points. ${ }^{8}$

PTA is a viable alternative to surgery with a low complication rate. However, post-PTA restenosis with Takayasu's arteritis has been reported to occur much frequently than in association with atherosclerotic diseases, particularly in diffuse and long stenotic lesions. ${ }^{4,5}$ At present, stent placement has rapidly gained acceptance for the treatment of Takayasu's arteritis; however, PTA for an In-Stent Restenosis [ISR] in association with Takayasu's arteritis rarely been documented. In this patient, we planned to do stage dilatation of abdominal aortic stent. Unfortunately because of reactivation of disease due to poor drug compliance and loss of follow up, the patient developed ISR of both aortic and right axillary stents. She underwent redo PTA with stenting of aortic ISR and discharged with the plan of axillary stenting after 6 months. The corticosteroid was reinitiated and she is planned for Mycophenolate mofetil should she develop resistance for steroids in future. It is important to control disease activity with newer immuno-suppressant like Mycophenolate mofetil, if it is not achieved by corticosteroids to prevent restenosis. ${ }^{9}$

\section{CONCLUSION}

Redo PTA with stenting and optimal disease modifying drugs is a good option for symptomatic abdominal aortic ISR in Takayasu's arteritis.

\section{REFERENCES}

1. Ishikawa $\mathrm{K}$, Maetani S. Long-term outcome for 120 Japanese patients with Takayasu's disease clinical and statistical analysis of related prognostic factors. Circulation 1994;90(4):1855-60.

2. Sawada S, Tanigawa N, Kobayashi M, et al. Treatment of Takayasu's arteritis with self-expanding metallic stent (giant-urco stent) in two patients. Cardiovasc Intervent Radiol 1994;17(2):102-5.

3. Arend WP, Michel BA, Bloch DA, et al. The American college of rheumatology 1990 criteria for the classification of Takayasu arteritis. Arthritis Rheum 1990;33(8):1129-34.

4. Joseph S, Mandalam KR, Rao VR, et al. Percutaneous transluminal angioplasty of the subclavian artery in nonspecific aorto-arteritis: results of long-term follow-up. J Vasc Interv Radiol 1994;5(4):573-80.

5. Tyagi S, Verma PK, Gambhir DS, et al. Early and long-term results of subclavian angioplasty in aorto-arteritis (Takayasu disease): comparison with atherosclerosis. Cardiovasc Intervent Radiol 1998;21(3):219-24.

6. Lupi-Herrera E, Sánchez-Torres G, Marcushamer J, et al. Takayasu arteritis. Clinical study of 107 cases. Am Heart J 1977;93(1):94-103.

7. Numano $F$, Okawara $M$, Inomata $H$, et al. Takayasu's arteritis. Lancet 2000;356(9234):1023-5.

8. Tada Y, Sato 0, Ohshima A, et al. Surgical treatment of Takayasu arteritis. Heart Vessels 1992;7(1):159-67.

9. Shinjo SK, Pereira RM, Tizziani VA, et al. Mycophenolate mofetil reduces disease activity and steroid dosage in Takayasu arteritis. Clin Rheumatol 2007;26(11):1871-5. 